\title{
Surveillance of extensively drug-resistant tuberculosis in Europe, 2003-2007
}

I Devaux (Isabelle.Devaux@ecdc.europa.eu) ${ }^{1,2}$, D Manissero3, K Fernandez de la Hoz ${ }^{3,4}$, K Kremer ${ }^{5}$, D van Soolingen ${ }^{5}$, on behalf of the EuroTB network ${ }^{6}$

1. EuroTB, Institut National de Veille Sanitaire (InVS), Saint Maurice, France affiliation where the work was performed)

2. Current affiliation: European Centre for Disease Prevention and Control (ECDC), Stockholm, Sweden

3. European Centre for Disease Prevention and Control, Stockholm (ECDC), Sweden

4. Current affiliation: Dirección General de Salud Pública y Sanidad Exterior, Madrid, Spain

5. National Institute for Public Health and the Environment (RIVM), Bilthoven, the Netherlands

6 . The members of the network are listed at the end of the article

Citation style for this article:

Citation style for this article: Devaux I, Manissero D, Fernandez de la Hoz K, Kremer K, van Soolingen D, on behalf of the EuroTB network. Surveillance of

extensively drug-resistant tuberculosis in Europe, 2003-2007. Euro Surveill. 2010;15(11):pii=19518. Available online: http://www.eurosurveillance.org/ViewArticle. aspx?Articleld $=19518$

This paper describes the results of second-line drug (SLD) susceptibility tests among multidrug-resistant tuberculosis (MDR TB) cases reported in 20 European countries aiming to identify extensively drug-resistant tuberculosis (XDR TB) cases. A project on molecular surveillance of MDR TB cases was conducted by EuroTB and the National Institute for Public Health and the Environment (RIVM) from 2005 to 2007. Information on drug susceptibility testing (DST) was provided to this project and case-based data on MDR TB cases were reported on a quarterly basis by 20 countries of the World Health Organization's European Region, including 15 European Union Member States. Data included SLD susceptibility test results, enabling a retrospective description of XDR TB cases notified between 2003 and 2007. In 18 countries DST was performed for two or more of the SLD included in the XDR TB definition. The proportion of MDR TB isolates tested for SLD varied widely between countries (range 20 to 100 percent). In the 18 countries, 149 (10\%) XDR TB cases were reported among MDR TB cases with available DST results for SLD. Sixteen additional MDR TB cases were reported by the MDR TB surveillance system when compared with the number of routinely reported MDR TB cases to EuroTB in ten countries with representative data reported during three consecutive years (2003-2005). To counter the threat of XDR TB in Europe, a standardised approach to XDR TB surveillance and DST for SLD is needed, as well as increased laboratory capacity across European countries.

\section{Introduction}

Extensively drug-resistant tuberculosis (XDR TB) is a worldwide threat to TB control, as XDR TB cases are extremely difficult to treat [1]. The origin of XDR TB is linked to the introduction of second-line antituberculosis drugs (SLD) for the treatment of multidrug-resistant tuberculosis (MDR TB) and the possible mismanagement of patients (including failure of compliance) under SLD treatment $[2,3]$. In March 2006, the term XDR TB first appeared in the literature in a United States Centers for Disease Control and Prevention (US $C D C$ ) report describing the findings of a worldwide survey on anti-TB drug resistance carried out between 2000 and 2004 [4]. Since then, a number of scientific and media reports on XDR TB have been published [5]. Although the term has emerged only recently, the occurrence of TB cases resistant to most available drugs is not new [6]. The definition of XDR TB, MDR TB plus resistance to a fluoroquinolone and at least one of three injectable SLD (amycacin, kanamycin, capreomycin) has been revised in 2006 because not all the SLD included in the original case definition were used and tested worldwide [7-9].

Epidemics of drug-resistant TB have been described in the WHO European Region since the 1990s [10]. XDR TB has been identified as a significant problem in countries of the former Soviet Union [11] and the potential threat of XDR TB for Europe has been assessed by the European Centre for Disease Centre and Prevention (ECDC) in 2006 [12]. The occurrence of XDR TB outbreaks in patients co-infected with HIV has re-enforced the public health awareness, with a particular focus on South Africa [13].

In 2005, the EuroTB network started a molecular surveillance project on MDR TB in 24 countries of the WHO European Region including 19 European Union (EU) Member States, plus Croatia, Israel, the Former Yugoslav Republic of Macedonia, Norway and Switzerland) [14]. The project was coordinated by EuroTB in France and the National Institute for Public Health and the Environment (RIVM) in the Netherlands until the end of 2007. As resistance to SLD was already a matter of concern in 2005, data on drug susceptibility testing (DST) for SLD were collected in addition to DNA fingerprint data $[14,15]$. The project provided an opportunity to implement case reporting of XDR TB by applying the revised XDR TB case definition of 2006 
retrospectively. This article describes notification data on resistance to SLD in the EU and some neighbouring countries from January 2003 through June 2007.

\section{Methods}

Data collection

The MDR TB project included 24 countries of the WHO European Region that were able to or planning to participate in case-based reporting of molecular data on MDR TB cases at European level in 2005. Case-based data on all newly diagnosed and culture confirmed positive MDR TB cases were reported by national surveillance institutions (NSI) to EuroTB on a quarterly basis from January 2005 through June 2007. Data for 2003 and 2004 were reported retrospectively. The data were collected anonymously, according to a standardised data file specification reviewed by the members of the EuroTB advisory committee [16]. Each case had a unique record identifier. Common definitions of variables were used by the participating countries, including demographic and clinical variables and results from susceptibility testing for first and second-line anti-TB drugs. The country of origin of a case was defined as

\section{TABLE 1}

Reporting of anti-tuberculosis second line DST on Mycobacterium tuberculosis isolates of MDR TB cases in 20 European countries, 2003-2007

\begin{tabular}{|c|c|c|c|c|c|c|c|}
\hline \multirow{3}{*}{ Country } & \multirow{3}{*}{$\begin{array}{c}\text { MDR TB } \\
\text { cases } \\
\text { N }\end{array}$} & \multirow{3}{*}{$\begin{array}{c}\text { Secondline } \\
\text { drugs tested } \\
\text { N }\end{array}$} & \multicolumn{3}{|c|}{ Injectable drugs } & \multicolumn{2}{|c|}{ Fluoroquinolones } \\
\hline & & & \multirow{2}{*}{$\begin{array}{c}\text { Amikacin } \\
\text { N (\%) }\end{array}$} & \multirow{2}{*}{$\begin{array}{c}\text { Kanamycin } \\
\mathrm{N}(\%)\end{array}$} & \multirow{2}{*}{$\begin{array}{c}\text { Capreomycin } \\
\text { N (\%) }\end{array}$} & \multirow{2}{*}{$\begin{array}{c}\text { Ciprofloxacin } \\
\text { N (\%) }\end{array}$} & \multirow{2}{*}{$\begin{array}{c}\text { Ofloxacin } \\
\mathrm{N}(\%)\end{array}$} \\
\hline & & & & & & & \\
\hline \multicolumn{8}{|c|}{ Five second line anti-tuberculosis drugs tested } \\
\hline France $^{2}$ & 152 & 5 & $148(97)$ & $147(97)$ & $135(89)$ & $145(95)$ & $149(98)$ \\
\hline Czech Republic ${ }^{1}$ & 38 & 5 & $25(66)$ & $22(58)$ & $25(66)$ & $25(66)$ & $25(66)$ \\
\hline Norway $^{1}$ & 11 & 5 & $11(100)$ & $11(100)$ & $11(100)$ & $5(45)$ & $11(100)$ \\
\hline Ireland $^{1}$ & 8 & 5 & $3(38)$ & $1(13)$ & $3(38)$ & $3(38)$ & $1(13)$ \\
\hline Slovenia $^{4}$ & 3 & 5 & $3(100)$ & $1(33)$ & $1(33)$ & $3(100)$ & $1(33)$ \\
\hline \multicolumn{8}{|c|}{ Four second line anti-tuberculosis drugs tested } \\
\hline Lithuania³ & 656 & 4 & $89(14)$ & $173(26)$ & $101(15)$ & $\cdots$ & $172(26)$ \\
\hline Estonia $^{2}$ & 248 & 4 & $245(99)$ & $245(99)$ & 244 (98) & $\cdots$ & $245(99)$ \\
\hline |srael $^{2}$ & 45 & 4 & $43(96)$ & $\cdots$ & $43(96)$ & $44(98)$ & $44(98)$ \\
\hline Switzerland $^{1}$ & 25 & 4 & $24(96)$ & $-\cdot$ & $9(36)$ & $4(16)$ & $19(76)$ \\
\hline Denmark $^{3}$ & 5 & 4 & $5(100)$ & $\cdots$ & $5(100)$ & $5(100)$ & $5(10)$ \\
\hline \multicolumn{8}{|c|}{ Three second line anti-tuberculosis drugs tested } \\
\hline Latvia $^{1}$ & 712 & 3 & $-\cdots$ & 705 (99) & $698(98)$ & $\cdots$ & $689(97)$ \\
\hline Romania $^{3}$ & 50 & 3 & $19(38)$ & $44(88)$ & $\cdots$ & $44(88)$ & $\cdots$ \\
\hline Belgium $^{1}$ & 31 & 3 & $12(39)$ & $2(6)$ & $\cdots$ & $\cdots$ & $12(39)$ \\
\hline Poland 4 & 17 & 3 & $6(35)$ & $\cdots$ & $6(35)$ & $\cdots$ & $6(35)$ \\
\hline $\begin{array}{l}\text { Former Yugoslavian Republic } \\
{\text { of } \text { Macedonia }^{1}}\end{array}$ & 15 & 3 & $8(53)$ & $-\cdot$ & $8(53)$ & $8(53)$ & $\cdots$ \\
\hline Cyprus $^{1}$ & 3 & 3 & $1(33)$ & $\cdots$ & $3(100)$ & $\cdots$ & $3(10)$ \\
\hline \multicolumn{8}{|c|}{ Two second line anti-tuberculosis drugs tested } \\
\hline The Netherlands ${ }^{2}$ & 34 & 2 & $33(97)$ & $\cdots$ & $\cdots$ & $34(100)$ & $\cdots$ \\
\hline Croatia $^{2}$ & 5 & 2 & $1(20)$ & $-\cdots$ & $\cdots$ & $2(40)$ & $\cdots$ \\
\hline \multicolumn{8}{|c|}{ One second line anti-tuberculosis drug tested } \\
\hline Spain $^{3}$ & 50 & 1 & $-\cdots$ & $2(4)$ & $-\cdots$ & $\cdots$ & $\cdots$ \\
\hline Sweden $^{1}$ & 21 & 1 & $15(71)$ & $\cdots$ & $\cdots$ & $\cdots$ & $\cdots$ \\
\hline Total & 2,129 & & $691(51)$ & $1,353(69)$ & $1,292(67)$ & $322(82)$ & $1382(71)$ \\
\hline
\end{tabular}

DST: drug sensitivity testing; MDR TB: multidrug-resistant tuberculosis.

Data reported between 2003 and 2007.

Data reported between 2003 and 2005.

3 Data reported between 2004 and 2005.

4 Data reported in 2005 and 2006 in Poland ; 2003 and 2005 in Cyprus; 2003, 2005 and 2006 in Slovenia. 
their country of birth (if available) or their country of citizenship.

\section{Reporting of drug susceptibility testing for} second-line drugs and XDR TB cases

DST results for SLD, resistant or susceptible, were collected for the following drugs: amikacin, kanamycin, capreomycin, ciprofloxacin, ofloxacin. The rationale behind the choice of the SLD tested was that they represented the most commonly used aminoglycosides (injectables) and fluoroquinolones. If no resistance is measured against the tested drugs within each of these two classes of drugs, it is unlikely that resistance can be found against other drugs from the same classes, because of cross-resistance. Data were validated by EuroTB, eventually completed by the reporting NSI and collated into a European MDR TB case database.

The revised 2006 XDR TB case definition was used for the analysis [8]. This definition refers to XDR TB as resistance to at least isoniazid and rifampicin as well as further resistance to a fluoroquinolone (ofloxacin, ciprofloxacin) and at least one second-line injectable aminoglycocide (amikacin, kanamycin and capreomycin).
The number and distribution of MDR TB isolates tested for anti-TB second-line DST as well as the number and proportion of XDR TB cases by country were calculated. The percentage of SLD tested (SLD testing percentage) for a given country was defined as the number of tests performed for a specific drug divided by the number of MDR TB cases reported in that country. The proportion of XDR TB cases was calculated using the number of MDR TB cases tested for SLD (included in the XDR TB definition) as a denominator.

As reported by EuroTB [17], anti-TB drug resistance surveillance (DRS) was performed on nationwide samples of TB cases in all 18 countries participating to the MDR TB project [14], except for Italy and Spain (partial coverage) and Poland (no information about representativeness available). Data from Romania was provided from a country-wide DST survey.

The number of MDR TB cases reported to the project was compared with the number of MDR TB cases reported to Euro-TB using drug resistance susceptibility data.

\section{TABLE 2}

Distribution of MDR and XDR TB cases by country reported in 18 European countries, 2003-2007

\begin{tabular}{|c|c|c|c|c|}
\hline $\begin{array}{l}\text { Country (number of TB cases } \\
\text { reported to EuroTB) }\end{array}$ & $\begin{array}{l}\text { MDR TB cases reported to } \\
\text { MDR TB project } \\
\text { N }\end{array}$ & $\begin{array}{c}\text { MDR TB isolates tested for } \\
2-5 \text { SLD } \\
\text { N (\%) }\end{array}$ & $\begin{array}{c}\text { XDR TB cases } \\
\text { N }\end{array}$ & $\begin{array}{c}\text { XDR among MDR TB cases } \\
\text { with SLD DST } \\
\%\end{array}$ \\
\hline \multicolumn{5}{|c|}{ Countries with at least $88 \%$ of MDR TB cases tested for two to five SLD } \\
\hline Latvia $(6,107)$ & 712 & $688(97)$ & 53 & 8 \\
\hline Estonia $(1,736)$ & 248 & $245(99)$ & 58 & 24 \\
\hline France $(16,986)$ & 152 & $149(98)$ & 1 & 1 \\
\hline Romania $(60,323)$ & 50 & $44(88)$ & 2 & 5 \\
\hline Israel $(1,454)$ & 45 & $44(98)$ & 2 & 5 \\
\hline Netherlands $(3,820)$ & 34 & $33(97)$ & 1 & 3 \\
\hline Switzerland $(2,303)$ & 25 & $22(88)$ & 0 & 0 \\
\hline Norway $(1,221)$ & 11 & $11(100)$ & 0 & 0 \\
\hline Denmark $(1,200)$ & 5 & $5(100)$ & 0 & 0 \\
\hline Slovenia $(1,049)$ & 3 & $3(100)$ & 1 & 33 \\
\hline Cyprus (102) & 3 & $3(100)$ & 0 & 0 \\
\hline Total & 1,288 & $1,247(97)$ & 118 & $9 \%$ \\
\hline \multicolumn{5}{|c|}{ Countries with less than $88 \%$ of MDR TB cases tested for two to five SLD } \\
\hline Lithuania $(5,088)$ & 656 & $173(26)$ & 25 & 14 \\
\hline Czech Republic (4199) & 38 & $25(66)$ & 5 & 20 \\
\hline Belgium $(4,187)$ & 31 & $12(39)$ & 0 & 0 \\
\hline Poland $(17,873)$ & 17 & $6(35)$ & 0 & 0 \\
\hline Macedonia $(2,662)$ & 15 & $8(53)$ & 0 & 0 \\
\hline Ireland $(1,747)$ & 8 & $3(38)$ & 1 & 33 \\
\hline Croatia $(3,931)$ & 5 & $1(20)$ & 0 & 0 \\
\hline Total & 770 & $228(30)$ & 31 & $14 \%$ \\
\hline Total & 2,058 & $1,475 \quad(72)$ & 149 & $10 \%$ \\
\hline
\end{tabular}

DST: drug sensitivity testing; MDR TB: multidrug-resistant tuberculosis, XDR TB: extensively drug-resistant tuberculosis; SLD: second line drugs.

${ }_{1}$ Data reported for at least one year between 2003 and 2007. 


\section{Results}

Individual data on SLD testing for Mycobacterium tuberculosis isolates from 2,129 cases reported between January 2003 and July 2007 were available for 20 countries (population of 259,467,657) out of 24 European countries (population of 467,007,506), including 15 EU countries. Data were not reported by Germany, Italy, Finland and the United Kingdom, representing almost half of the total population covered by the surveillance project.

Sixteen additional MDR TB cases were reported by the MDR TB surveillance system when compared with the number of routinely reported MDR TB cases to EuroTB in ten countries with representative data reported during three consecutive years (2003-2005) (i.e. Belgium, Denmark, Estonia, Ireland, Israel, Latvia, Netherlands, Norway, Slovenia, Switzerland) [17].

\section{Number of second-line anti-TB drugs}

tested for susceptibility by country

The number of SLD tested varied from one to five by country (Table 1).

In the five countries where SLD testing was reported for all five drugs; France, Czech Republic, Norway, Ireland, and Slovenia, the proportion of MDR TB cases tested (SLD testing percentages) varied from $\geq 13 \%$ in Ireland to $\geq 58 \%$ in the Czech Republic, and $\geq 89 \%$ in France. In countries where DST was performed for four SLD, ciprofloxacin was not tested in Lithuania and Estonia, and kanamycin was not tested in Israel, Switzerland, and Denmark. Testing percentages were very high ( $\geq 96 \%)$ in Estonia and Israel for all the SLD tested. In contrast, testing percentages were low in Lithuania ( $\leq 26 \%)$.

In the six countries where DST was performed for three drugs, amikacin was included in testing practices in all the countries, except in Latvia. DST was performed for two drugs (amikacin and ciprofloxacin) in the Netherlands (testing percentage $\geq 97 \%$ ) and Croatia (testing percentage $\leq 40 \%$ ). Two countries, Sweden and Spain tested for one SDL.

In six countries (Norway, Ireland, Slovenia, Denmark, Cyprus and Croatia), the numbers of MDR TB cases reported was small and therefore the results for those countries do not necessarily reflect the testing practices in these countries.

\section{XDR TB cases reported by country}

The number of XDR TB cases was calculated for the 18 countries where MDR TB isolates were tested for at least two SLD (Table 2). When considering the proportion of MDR TB cases tested for SLD, two groups of countries could be distinguished: group 1, countries with a high ( $\geq 88 \%$ ) percentage of SLD testing and group 2 , countries with a low $(\leq 88 \%)$ percentage of SLD testing (Table 2 ). The ten countries in group 1 represented $63 \%(1,288 / 2,058)$ of reported MDR TB cases and $79 \%$ of the identified XDR TB cases.
XDR TB cases were detected in 10 countries, of which nine are EU Member States, and seven belonged to group 1. The overall proportion of XDR TB cases among MDR TB cases with DST for SLD was $10 \%$. Ninety-one percent $(136 / 149)$ of the XDR TB cases detected were reported in the Baltic States, where the percentage of XDR TB among MDR TB patients tested for SLD was $8 \%$ or higher (Table 2). In Estonia, 24\% of MDR TB cases with DST results for SLD were XDR. This percentage is based on a highly representative sample of $99 \%$ of MDR TB patients tested for SLD. Therefore, this result indicates a relatively high prevalence of XDR TB among MDR TB cases in this country. In Latvia, where SLD results were available for $97 \%$ of MDR TB, the proportion of XDR TB was three times lower than in Estonia. In Lithuania, the proportion of XDR TB (14\%) was based on a sample of 173 MDR TB cases with DST results. These 173 patients represent $26 \%$ of all reported MDR TB cases, which may not have been selected randomly meaning that only the most severe cases may have been tested for SLD. In the Czech Republic, the percentage of XDR TB cases was relatively high (20\%), but the information for SLD testing was only available for 25 cases, representing $66 \%$ of the Czech MDR TB cases reported to our project.

\section{Discussion}

This surveillance-based project provides baseline data on XDR TB in a large number of European countries at the time of the establishment of the XDR TB case definition. Although four western European countries with a large population were not included in this project, results show that at least one XDR TB case was reported in 10 out of 18 European countries. The overall proportion of XDR TB among 1,475 (72\%) MDR TB patients tested for SLD was approximately $10 \%$. Ninety-one percent of the reported 149 XDR TB cases were notified by the three Baltic countries (Estonia: 248 cases, Latvia: 712 cases, Lithuania: 656 cases), which belonged to the former Soviet Union until 2004. This confirms the finding of a worldwide survey conducted by WHO and the US CDC, showing that the proportion of XDR TB among TB patients originating from former Soviet Union countries is high. [18].

These data have to be interpreted in a broader scope of the establishment of TB surveillance and control in the WHO European Region $[19,20]$. The number of XDR TB cases detected can partly be affected by differences in surveillance systems between countries for case definitions, the possibility of linking laboratory and notification data, and by data quality (completeness and validity). The revision of the XDR TB definition had an impact on the determination of the number of XDR TB cases in European countries [8]. According to the previous case definition, the proportion of XDR among MDR TB cases was estimated to be higher in 17 countries [12].

The fact that 20 out of 24 participating countries reported SLD test results for at least one drug, and that 
DST for SLD was performed but not available for reporting in at least one other country, the United Kingdom, is a positive indicator for the availability of DST for SLD at European level. However, the number of XDR TB cases reported could be underestimated because of the limited number of SLD susceptibility testing in some countries or over-estimated due to lack of standardisation.

The number and type of SLD tested varied considerably between countries. A lack of standardisation and homogeneity in drug susceptibility testing practices for SLD has been identified by a panel of laboratory experts [21]. However, susceptibility testing of SLD has yielded reliable and reproducible results for some of the SLD [22]. Cross-resistance is common among aminoglycosides and absolute among fluoroquinolones, however, not all isolates exhibit the same resistance profile. Despite issues related to cross-resistance, it remains important to test a broad panel of SLD [23]. At the time of reporting, SLD DST methods had not been standardised or recommended, and External Quality Assurance (EQA) was not available, but since 2007 EQA for SLD has begun and since 2008 policy guidance has been published, which should help in standardising testing practices [21]. Therefore, it is expected that SLD DST practices and standardisation of these will improve significantly within the coming years.

The findings of this project and previous ones $[14,18]$ concerning the relatively high rate of $10 \%$ XDR among MDR TB cases, should have an impact on clinical management of individual patients and TB control, especially in eastern European countries. There is a need for new drugs and treatment strategies. However, while new drugs will only be available in a number of years, the utility of derivates of current drugs and also alternative drugs like meropenem should be explored [24]. Serious consequences for TB control may be related to increased travel and migration, as this can lead to imported cases MDR TB from eastern Europe to western Europe, and transmissible forms of MDR and XDR TB are a fearsome scenario [14]. If transmission of XDR TB is diagnosed in western European countries, new strategies on monitoring risks associated with immigration from and travel to high-incidence settings should be developed.

Our surveillance project has some limitations that should be taken into account in future MDR and XDR TB surveillance in Europe. It would be of considerable value if data from the four missing countries could be added. In countries with a low proportion of patients tested for SLD, (Lithuania, Czech Republic), additional data is needed to better interpret the XDR TB prevalence. In countries with low numbers of XDR TB cases reported (e.g. Ireland and Slovenia), XDR TB percentages can be biased and therefore should not be compared to other countries.

\section{Conclusion}

Further research are conducted on the occurrence of transmitted MDR and XDR TB strains to investigate whether they pose a new evolutionary development of M. tuberculosis, or an extend of the current problem. Both scenarios would highlight consequences of a long lasting, uncontrolled problem and demonstrate the need for enhanced efforts in TB control in the regions where this problem develops. The capacity for SLD testing should be upgraded, especially in areas with high numbers of drug-resistant TB cases, such as in eastern Europe. As identified in a previous survey [25], standardisation and quality assurance of laboratory methods for DST of SLD should be improved across Europe. An EU reference laboratory network has been established with EU Member States to support their activities [26]. Surveillance data on MDR and XDR TB with improved quality are essential to determine the magnitude of this threat to TB control. In addition, surveillance data is needed to monitor TB control activities, and as a basis for implementing appropriate treatment and care and to prioritise laboratory resources.

The members of the EuroTB network were: M Wanlin, Belgium; G Vankerschaever, Belgium; M Fauville-Dufaux, Belgium; F Portaels, Belgium; A Simunovic, Croatia; V Katalinic-Jankovic, Croatia; D Pieridou-Bagatzouni, Cyprus; M Havelkova, Czech Republic; V Ostergaard Thomsen, Denmark; Z Kamper Jorgensen, Denmark; V Hollo, Estonia; T Kummik, Estonia; P Ruutu, Finland; M Marjamaki, Finland; J Makinen, Finland; D Che, France; D Antoine, France; C Gutierrez, France; J Robert, France; W Haas, Germany; B Brodhun, Germany; S Rüsch-Gerdes, Germany; S Niemann, Germany; J O’Donnell, Ireland; T Rogers, Ireland; M G Pompa, Italy; D Cirillo, Italy; A Gori, Italy; D Chemtob, Israel; D Goldblatt, Israel; V Riekstina, Latvia; G Skenders, Latvia; A Sosnovskaja, Lithuania; P Stakenas, Lithuania; A Vidoevska, Macedonia; H Heersma, The Netherlands; C Erkens, The Netherlands; B Askeland Winje, Norway; U R Dale, Norway; Z Zwolska, Poland; E Ibraim, Romania; D I Chiotan, Romania; I Solovic, Slovakia; J Trenkler, Slovakia; D Erzen, Slovenia; M Zolnir-Dovc, Slovenia; E Rodriguez Valin, Spain; S Samper, Spain; J Iglesias, Spain; V Romanus, Sweden; S Hoffner, Sweden; G Källenius, Sweden; P Helbling, Switzerland; B Springer, Switzerland; E C Boettger, Switzerland; J Watson, United Kingdom; I Abubakar, United Kingdom, Francis Drobniewski, United Kingdom.

\section{Acknowledgements}

We would like to thank the following contributors to this paper: Dennis Falzon, Andrea Infuso, Jean-Claude Desenclos, Delphine Antoine and Didier Che from the Institut National de Veille Sanitaire, in Paris, France as well as the members of the EuroTB Advisory Committee: Luke Clancy, Michael Forssbohm, Jean-Paul Klein, Maria Korzeniewska-Kosela, Vincent Kuyvenhoven and Richard Zaleskis. We also would like to thank Andrea Ammon, Abigail Wright, Mateo Zignol.

The sources of financial support are the European Commission, DG-SANCO under the grant agreement no 2004213 and the Institut National de Veille Sanitaire, France.

\section{References}

1. Bonilla CA, Crossa A, Jave HO, Mitnick CD, Jamanca RB, Herrera $C$, et al. Management of extensively drug-resistant tuberculosis in Peru: cure is possible. PLoS One. 2008;3(8):e2957.

2. Matteelli A, Migliori GB, Cirillo D, Centis R, Girard E, Raviglion $M$. Multidrug-resistant and extensively drug-resistant Mycobacterium tuberculosis: epidemiology and control. Expert Rev Anti Infect Ther. 2007;5(5):857-71.

3. Migliori GB, Besozzi G, Girardi E, Kliiman K, Lange C, Toungoussova OS, et al. Clinical and operational value of the extensively drug-resistant tuberculosis definition. Eur Respir J. 2007;30(4):623-6. 
4. Centers for Disease Control and Prevention (CDC). Emergence of Mycobacterium tuberculosis with extensive resistance to second-line drugs - worldwide, 2000-2004. MMWR Morb Mortal Wkly Rep. 2006;55:301-5.

5. Goldman C, Kevin V, Plumley, Laughon BE. The evolution of extensively drug resistant tuberculosis (XDR TB): History, status and issues for global control. Infectious Disorders Drug Targets. Volume 7, Number 2, June 2007, p. 73-91(19).

6. Guerrero A, Cobo J, Fortún J. Navas E, Quereda C, Asensio A, et al. Nosocomial transmission of Mycobacterium bovis resistant to 11 drugs in people with advanced HIV-1 infection. Lancet. 1997;350(9093):1738-42.

7. Alexander PE, De P. The emergence of extensively drugresistant tuberculosis (TB): TB/HIV coinfection, multidrugresistant $T B$ and the resulting public health threat from extensively drug-resistant TB, globally and in Canada. Can J Infect Dis Med Microbiol. 2007;18(5):289-91.

8. Manissero D, Fernandez de la Hoz K. Surveillance methods and case definition for extensively drug resistant TB (XDR TB) and relevance to Europe: summary update. Euro Surveill. 2006;11(44). pii=3070. Available from: http://www. eurosurveillance.org/ViewArticle.aspx?Articleld=3070

9. Centers for Disease Control and Prevention (CDC). Extensively drug-resistant tuberculosis--United States, 1993-2006. MMWR Morb Mortal Wkly Rep. 2007;56(11):250-3.

10. Aziz MA, Wright A, Laszlo A, De Muynck A, Portaels F, Van Deun A, et al. . Epidemiology of antituberculosis drug resistance (the Global Project on Anti-tuberculosis Drug Resistance Surveillance): an updated analysis. Lancet 2006;368(9553):2142-54.

11. World Health Organization/International Union Against TB and Lung Disease Global Project on Anti-Tuberculosis Drug Resistance Surveillance. Anti-Tuberculosis Drug Resistance in the World: Fourth Global Report. 2008. Available from: http:/ www.who.int/tb/publications/2008/drs_report4_26febo8.pdf

12. Manissero D, Fernandez de la Hoz K. Extensive drug-resistant TB: a threat for Europe? Euro Surveill. 2006;11(39). pii=3056. Available from: http://www.eurosurveillance.org/ViewArticle. aspx?Articleld $=3056$

13. Gandhi NR, Moll A, Sturm AW, Pawinski R, Govender T, Lalloo $\mathrm{U}$, et al. Extensively drug-resistant tuberculosis as a cause of death in patients co-infected with tuberculosis and HIV in a rural area of South Africa. Lancet. 2006;368(9547):1575-80.

14. Devaux I, Kremer K, Heersma H, Van Soolingen D. Clusters of multidrug-resistant Mycobacterium tuberculosis cases, Europe. Emerg Infect Dis. 2009;15(7):1052-60.

15. World Health Organization/International Union Against TB and Lung Disease Global Project on Anti-Tuberculosis Drug Resistance Surveillance. Anti-tuberculosis drug resistance in the world. Report no. 3. 2008 Available from: http://www.who. int/tb/publications/who_htm_tb_2004_343/en/

16. EuroTB. European surveillance of multidrug resistant tuberculosis EuroTB/RIVM. Main Data File Specification for reporting MDR-TB cases. Summary version October 2005. Available from: http://www.eurotb.org/mdr_tb_surveillance/ pdf/dfs_nsi_short.pdf

17. EuroTB and the national coordinators for tuberculosis surveillance in the WHO European Region. Surveillance of tuberculosis in Europe. Report on tuberculosis cases notified in 2006, Institut de veille sanitaire, Saint-Maurice, France. March 2008. Available from: http://www.eurotb.org/rapports/2006/ full_report.pdf

18. Shah NS, Wright A, Bai GH, Barrera L, Boulahbal F, MartínCasabona N, et al. Worldwide emergence of extensively drugresistant tuberculosis. Emerg Infect Dis. 2007;13(3):380-7.

19. Broekmans JF, Migliori GB, Rieder HL, Lees J, Ruutu P, Loddenkemper R, et al. European framework for tuberculosis control and elimination in countries with a low incidence. Recommendations of the World Health Organization (WHO), International Union Against Tuberculosis and Lung Disease (IUATLD) and Royal Netherlands Tuberculosis Association (KNCV) Working Group. Eur Respir J. 2002 Apr;19(4):765-75.

20. Mor Z, Migliori GB, Althomsons SP, Loddenkemper R, Trnka $\mathrm{L}$, lademarco MF. Comparison of tuberculosis surveillance systems in low-incidence industrialised countries. Eur Respir J. 2008;32(6):1616-24.

21. World Health Organization (WHO). Policy guidance on drugsusceptibility testing (DST) of second-line antituberculosis drugs. WHO/HTM/TB/2008.392. Geneva 2008. Available from: http://www.who.int/tb/features_archive/xdr_mdr_policy guidance/en/index.html

22. Rüsch-Gerdes, S, Pfyffer GE, Casal M, Chadwick M, Siddiqi S. Multicenter laboratory validation of the BACTEC MGIT 960 technique for testing susceptibilities of Mycobacterium tuberculosis to classical second-line drugs and newer antimicrobials. J Clin Microbiol 2006;44(3):688-92.
23. van Ingen J, Boeree MJ, Wright A, van der Laan T, Dekhuijzen PNR, van Soolingen D. Second-line drug resistance in multidrug-resistant tuberculosis cases of various origins in the Netherlands. Int. J. Tuberc Lung Dis. 2008;12(11):1295-9.

24. Hugonnet JE, Tremblay LW, Boshoff HI, Barry CE 3rd, Blanchard JS. Meropenem-clavulanate is effective against extensively drug-resistant Mycobacterium tuberculosis. Science. 2009;323(5918):1215-8.

25. Drobniewski F, Rüsch-Gerdes S, Hoffner S, Subcommittee on Antimicrobial Susceptibility Testing of Mycobacterium tuberculosis of the European Committee for Antimicrobial Susceptibility Testing (EUCAST) of the European Society of Clinical Microbiology and Infectious Diseases (ESCMID). Antimicrobial susceptibility testing of Mycobacterium tuberculosis (EUCAST document E.DEF 8.1) -- report of the Subcommittee on Antimicrobial Susceptibility Testing of Mycobacterium tuberculosis of the European Committee for Antimicrobial Susceptibility Testing (EUCAST) of the European Society of Clinical Microbiology and Infectious Diseases (ESCMID). Clin Microbiol Infect. 2007;13 (12):1144-56.

26. Drobniewski FA, Nikolayevskyy V, Hoffner S, Pogoryelova 0 , Manissero D, Ozin AJ. The added value of a European Union tuberculosis reference laboratory network - analysis of the national reference laboratory activities. Euro Surveill. 2008;13(12). pii=8076. Available from: http://www. eurosurveillance.org/ViewArticle.aspx?Articleld $=8076$ 